\title{
One Academic Year Under COVID-19 Conditions: A Multicenter Evaluation Study Among Medical Students in Bavaria, Germany Students' Needs, Difficulties, and Concerns About Digital Teaching and Learning
}

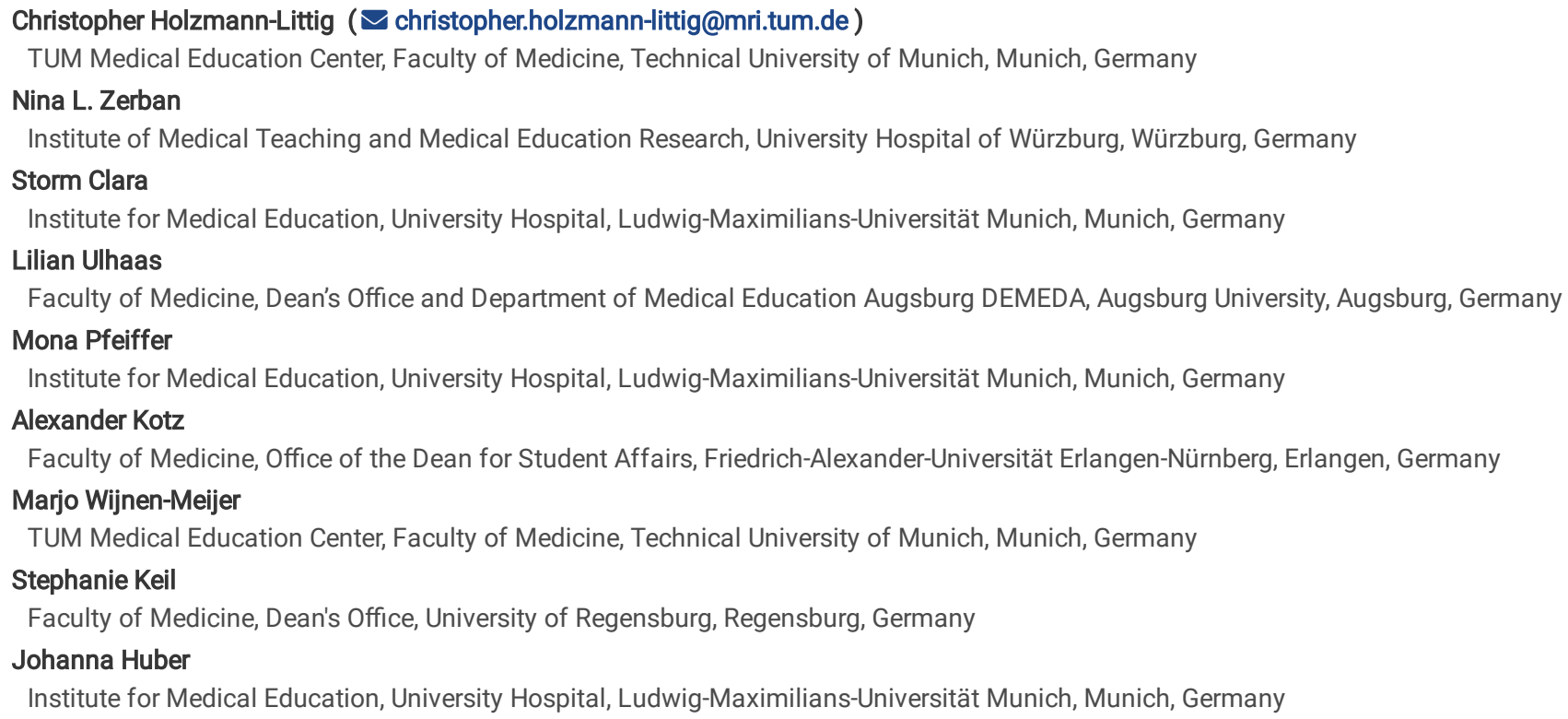




\section{Abstract \\ Background}

Since March 2020, COVID-19 has created a need for adaptation in many areas of life. This study explores medical students' perspectives on digital teaching under conditions of the COVID-19 pandemic. It focuses on expectations and concerns about digital teaching, the evaluation of specific aspects of teaching, and requests for future teaching.

\section{Methods}

Six German faculties have joined forces within the Bavarian network for medical education to develop and deploy a common core questionnaire. Crosssectional surveys were conducted at the end of the summer semester 2020 and winter semester 2020/21. Medical students from different semesters participated in the online survey. Data was analyzed descriptively and/or inferentially. Item differences across semesters were examined using contingency tables and $\mathrm{Chi}^{2}$ tests. Mean values were compared using the independent samples t-test; answer frequencies in retrospective and prospective concerns were compared using contingency tables and $\mathrm{Chi}^{2}$ tests with Yates' correction.

\section{Results}

In the summer semester 2020, 1565 students and in winter semester 2020/21, 1727 students took part in the survey. Students' ratings on aspects of the organizational framework, for example knowledge of where to find information or the helpfulness of information, were in the upper-middle range. Of the students, $92.5 \%$ in the summer semester and $93.7 \%$ in winter semester had access to technical equipment to participate in synchronous online sessions. For some students, however, the internet connection was not stable enough to do so. Students particularly missed the personal contact with their fellow students, but also with teachers. On-site teaching was the preferred form of teaching, and there was a preference for asynchronous over synchronous digital teaching. Teaching recordings were particularly popular to complement future on-site teaching. Besides the lack of social exchange with fellow students, the students' biggest concern was the lack of possibility to perform practical trainings.

\section{Conclusions}

The following areas of education under COVID-19 conditions are highly important to medical students: adequacy of information sharing, integration of opportunities for exchange with fellow students and teachers, possibility to perform practical trainings. After the normalization of the pandemic situation, on-site teaching should be supplemented with blended learning concepts such as the inverted classroom model.

\section{Background}

With the emergence of the Coronavirus SARS-CoV-2 (COVID-19) pandemic and the associated government-imposed public health measures (e.g. comprehensive hygiene measures, physical distancing, quarantine, travel restrictions) [1], universities around the world were forced to switch in a rush from predominantly on-site teaching to digital teaching at the beginning of the summer semester 2020 [2].

Medical schools in Germany and around the world had to adapt their curricula to the new situation as quickly as possible [3-6]. Some of them were able to draw on experience and existing concepts in digital teaching, such as blended learning and the inverted classroom method [7-9]. Others could only refer to little or no experience in digital teaching [10]. Nevertheless, medical schools around the world had one thing in common: all available resources had to be mobilized to set up an emergency remote teaching with the help of practical and creative solutions [11].

According to systematic reviews, digital medical teaching can be effective [12]; useful approaches include telehealth, social media and video conferencing [13]. Nonetheless, digital approaches are not equally well suited to all teaching formats, and particular difficulties arise in implementing hands-on, patientcentered teaching [14].

Parallel to the conversion of teaching and testing, medical schools developed concepts for the evaluation of digital teaching. On the one hand, to be able to ensure the quality of teaching despite this exceptional situation. On the other hand, to be able to answer, among others, the following questions [3, $5,8,10$, 15-24]:

- How is digital teaching designed within the curriculum? Which concepts, methods, tools, digital platforms and software programs are used to teach content?

- What do students and teachers particularly like about digital teaching?

- What are conducive or hindering factors with regard to the implementation of digital teaching concepts and the participation of students in digital teaching?

- Which digital teaching concepts should be maintained beyond the COVID-19 pandemic and how can they be implemented in the curricula in a didactically valuable way? 
Some medical schools have also investigated the cognitive, emotional and psychological effects of the COVID-19 pandemic and the resulting digital teaching on their students [4, 25-27]. Medical students have been and continue to be on the front lines of pandemic response. For this, structured preparation, such as that provided by the sample course by Ashcroft and colleagues, is essential [28], but there must also be clearly delineated role definitions [29].

According to a Best Evidence Medical Education (BEME) scoping review, previous publications on medical teaching under COVID-19 conditions focused primarily on the issues of simulation and distance teaching and provided evidence of the importance of collaboration [30]. Around the world, medical schools have undertaken extensive evaluation efforts $[8,10,25,26]$. Some of them have developed a regional or even national strategy for evaluating digital teaching $[4,5,9,31,32]$. In Germany, national institutions for higher education development, such as the Centre for Higher Education (Centrum für Hochschulentwicklung; CHE), the German Centre for Higher Education Research and Science Studies (Deutsches Zentrum für Hochschul- und Wissenschaftsforschung; DZHW) or the Institute for Higher Education Development (Institut für Hochschulentwicklung; HIS), have conducted national surveys on the quality and future of digital teaching at German universities $[2,7,33,34]$. However, evaluation data on digital teaching at medical schools based on jointly developed questionnaires is scarce.

For this reason, medical faculties have joined forces within the Competence Network Medical Education in Bavaria (Kompetenznetz Medizinlehre Bayern; $\mathrm{KMB}$ ) to be able to generate cross-site evaluation results and conclusions for digital teaching. Our research questions were:

1. How do medical students in Bavaria perceive the ad hoc conversion to pure digital teaching? What are their concerns and expectations?

2. Which aspects of digital teaching do medical students in Bavaria consider to be particularly successful? What would they like to maintain in the future?

3. Which aspects need to be improved with regard to future digital teaching?

\section{Methods}

We conducted a survey among medical students in Bavaria (Germany) at six medical schools: Universität Augsburg (UniA); Friedrich-Alexander-Universität Erlangen-Nürnberg (FAU); Ludwig-Maximilians-Universität München (LMU); Technische Universität München (TUM); Universität Regensburg (UR); JuliusMaximilians-Universität Würzburg (JMU). The aim was to investigate students' assessment of medical education under COVID-19 conditions. This study refers to the summer semester 2020 (courses taught from April to July 2020; this was the first semester affected by COVID-19) and winter semester 2020/21 (courses taught from October 2020 to February 2021). The survey waves took place from July 2020 to October 2020 and from January 2021 to April 2021.

In total, 7053 students in the summer semester 2020 and 8279 students in winter semester 2020/21 were asked to participate in the study. All students participated voluntarily and completely anonymously. We sent invitations by E-mail at all sites and conducted the survey using the evaluation software EvaSys (evasys $\mathrm{GmbH}$ ) as part of the respective semester evaluation.

At FAU[1] and JMU, all human medicine students were surveyed. LMU and UR chose to survey only students in the clinical phase of their studies. At UniA, the human medicine program had only begun in the winter semester 2019/20, so it was not possible to survey students in higher semesters there. For the summer semester, no data is available from TUM, as this site had already conducted an independent survey in advance. In the winter semester, students from the clinical phase took part in the survey as the pre-clinical phase is being held at LMU for students from TUM and LMU together.

The core questionnaire contains 29 questions in total (20 closed and 9 open ones). In this study, we focus on the closed questions. Questions with related content were combined into one question group. In total, the questionnaire consists of five question groups:

- Organizational framework

- Technological framework

- Communication and interaction

- Online teaching

- Overall assessment

For questions on the functionality of the personal technical equipment and the internet connection, the answer options Yes / Partially / No were formed. For questions on preferred means of communication, time of day for working on learning materials, online activities, and expressed concerns the respective options were offered for selection (selected / not selected). If "other" was selected, free text entry was allowed. The offered teaching forms could be prioritized in descending order. For questions involving a strength of agreement, 5-point Likert scales were formed. The complete questionnaire is available in German (original) and an English version (translation) in supplement 1. The terms "online teaching" and "digital teaching" were used synonymously in the questionnaire.

A detailed description of the survey procedure can be found in supplement table 2. The CHERRIES checklist for reporting online surveys [35] was applied for this purpose. Incomplete questionnaires were included in the analysis, the percentages are corrected for the respective number of responding students. 
Statistical analysis was performed using JASP, version 0.14.1 [36]. Descriptive results were output as frequencies, mean values and standard deviation, or minimum and maximum. Contingency tables were formed and $\mathrm{Chi}^{2}$ tests were performed to determine differences between items in the summer and winter semester groups. Mean value comparisons were performed using the independent samples t-test. Comparisons of answer frequencies in retrospective and prospective concerns were performed with contingency tables, using a Chi ${ }^{2}$ test with Yates' correction in the GraphPad calculator [37]. The template for figure 1 was created in $\mathrm{R}$ (version 4.0.4) with the package raster [38]. Bar charts were created using Microsoft Excel. A $p$-value of 0.05 was considered statistically significant.

\section{Footnote:}

[1] At FAU there are two human medicine courses of study: Medicine and Medicine Erlangen-Nürnberg/Bayreuth. The latter is a degree program with clinical education at the Medical Campus Upper Franconia in cooperation with the Campus Hospital Bayreuth. Both courses of study were surveyed.

\section{Results}

The main findings from the study are highlighted below. Quantitative results for all questions asked in the core questionnaire can be found in supplement table 3.

\section{Participants}

Over both survey waves, a total of 3292 data sets could be evaluated, which corresponds to a response rate of $22.2 \%$ (summer semester) and $20.9 \%$ (winter semester) respectively. The number of data sets per site can be seen in figure 1 .

Figure 1: Number of data sets per site. Total participants: 3292. $n=$ number of participants per site, $\%=$ percent of total participants across both semesters; S = summer semester 2020, W = winter semester 2020/21, JMU = Julius-Maximilians-Universität Würzburg, FAU = Friedrich-Alexander-Universität ErlangenNürnberg, UR = Universität Regensburg, UniA = Universität Augsburg, TUM = Technische Universität München, LMU = Ludwig-Maximilians-Universität München. Percentages do not add up to $100 \%$ due to rounding.

\section{Organizational framework}

In the summer semester, students $(n=1500)$ agreed with an average of $3.7(S D=1.1)$ with the statement that they knew where to find information on the module[2] and/or semester schedule - in the winter semester $(n=1695)$ this agreement was slightly stronger with an average of $4.0(S D=1.0) ; p \leq 0.001$.

Students considered the information provided also nearly as helpful in the summer semester $(n=1496, M=3.8, S D=0.9)$ as in the winter semester $(n=$ $1689, M=3.9, S D=0.9) ; p \leq 0.001$.

However, students in the winter semester reported knowing a little more clearly whom to contact with questions (summer semester: $n=1485, M=3.6, S D=$ 1.2; winter semester: $n=1674, M=3.8, S D=1.2 ; p \leq 0.001$ ).

\section{Technological framework}

Students most commonly used laptops both in the summer semester $(85.5 \%, n=1303)$ and the winter semester $(86.4 \%, n=1492)$. Tablets were used the second most in both semesters (summer: $42.2 \%, n=643$; winter: $41.2 \%, n=712$ ). Smartphones played a minor role for studying with $15.8 \%$ ( $n=241$ ) mentions in the summer semester and $11.1 \%(n=192)$ in the winter semester. The decrease in smartphone use was statistically significant ( $p \leq 0.001)$. In the summer semester, $10.6 \%(n=162)$ of the responding students primarily used a desktop PC for learning; this tendency was stable in the winter semester at $12.6 \%(n=217)$.

In the summer semester, $92.5 \%(n=1389)$ of students reported being able to participate in synchronous online sessions with their technical equipment; this proportion was similar in the winter semester with $93.7 \%(n=1594)$.

A webcam was available to $90.7 \%(n=1361)$ of the participants in the summer semester and $92.7 \%(n=1570)$ of the participants in the winter semester; $p$ $=0.002$.

In the summer semester, $83.0 \%(n=1247)$ of students reported that their internet connection was stable enough to view instructional videos; in the winter semester, this was the case for $83.5 \%(n=1419)$.

However, only $62.6 \%(n=940)$ of the participants in the summer semester and $60.6 \%(n=1030)$ of the participants in the winter semester considered the internet connection stable enough for participation in interactive, synchronous online sessions.

\section{Communication with teachers}

In both semesters, students agreed with the statement about missing the personal contact with teachers. However, this agreement was more pronounced in the winter semester (summer semester: $n=1539, M=3.6, S D=1.2$; winter semester: $n=1690, M=3.8, S D=1.2 ; p \leq 0.001$ ).

Students primarily held contact with the faculty via E-mail in both semesters. Learning platforms were used second most often for this purpose. Video conferencing systems were used third most often. On-site meetings, phone, WhatsApp or similar, Facebook, Instagram and Twitter played a minor role in 
communication. The means of communication used between students and teachers are shown in figure 2a.

\section{Communication with fellow students}

In the summer semester $(n=1543)$, students agreed with the statement that they missed the personal contact with fellow students with an average of 4.4 $(S D=1.0)$; in the winter semester $(n=1692)$ they agreed even more strongly, on average with $4.6(S D=0.9) ; p \leq 0.001$.

In the communication between fellow students, WhatsApp or similar appeared to be most important. This was followed by on-site meetings, phone calls, video conferencing, Instagram and Facebook. E-mails, learning platforms and Twitter played minor roles. The tools used in communication among fellow students are shown in figure $2 b$.

\section{Comparison with the previous semester}

All in all, students neither agreed nor disagreed that the current semester was much more exhausting than the previous one (summer semester $n=1408$, $M=3.1, S D=1.4$; winter semester $n=1444, M=3.1, S D=1.4) ; p=0.675$.

\section{Prioritization of teaching forms}

When asked about their preferred way of teaching, on-site teaching ranked number one by $55.5 \%(n=767)$ in the summer semester and $65.7 \%(n=1031)$ in the winter semester. Asynchronous digital teaching was second most often ranked number one (summer semester: $27.4 \%, n=378$; winter semester: $21.0 \%$, $n=329$ ). Synchronous online teaching was the least often prioritized form of teaching (summer semester: $17.1 \%, n=236$; winter semester: $13.3 \%, n=209$ ).

\section{Preferred future form of teaching}

When asked about online activities that should be kept for the future to supplement traditional on-site teaching, students most often selected teaching recordings. Scripts, etc. (e.g. slides, summary, journal article) were chosen second most often. Online self-tests were requested by more than half of the students in both the summer and winter semester.

The evaluation of different online activities to complement traditional on-site teaching in the future can be seen in figure 3.

\section{Students' concerns}

In both survey waves, students were asked retrospectively about their concerns at the beginning of the respective semester and asked prospectively about their concerns regarding the upcoming semester.

Regarding the beginning of the summer semester 2020, students' most often reported concern (78.8\%) was not being able to perform practical trainings. This was reported less often (66.7\%) regarding the upcoming winter semester $2020 / 21$. In the second survey round, $80.0 \%$ of the students expressed this concern retrospectively for the beginning of the winter semester $2020 / 21$ and $68.8 \%$ prospectively regarding the upcoming summer semester 2021 .

The second strongest concern (78.3\%) at the beginning of the summer semester 2020 was a lack of social exchange with fellow students. This significantly decreased to $64.2 \%$ regarding the upcoming winter semester $2020 / 21$. In the second survey round, this concern was reported most often with $84.3 \%$ for the beginning of the winter semester $2020 / 21$ and was still present at a high level with $75.9 \%$ regarding the upcoming summer semester 2021 .

The third strongest concern regarding the beginning of the summer semester 2020 was poor information about the organization from the part of the faculty with $71.2 \%$. This concern was expressed by $37.6 \%$ regarding the upcoming winter semester $2020 / 21$. In the second survey round, it was at $55.4 \%$ regarding the beginning of the winter semester 2020/21 and at 31.4\% regarding the upcoming summer semester 2021.

Concerns regarding the personal digital knowledge or technical equipment as well as concerns regarding the ability to use the learning platform were much less pronounced among students. The item regarding concerns about an insufficient integration of on-site and digital teaching was only asked in relation to the following semester.

Figure 4a shows retrospective and prospective student concerns as surveyed at the end of the summer semester 2020 . Figure $4 \mathrm{~b}$ shows retrospective and prospective student concerns as surveyed at the end of the winter semester 2020/21.

\section{Footnote:}

[2] only asked at LMU and TUM

\section{Discussion}

In summary, this study exposes the following areas for further development of medical teaching under COVID-19 conditions at Bavarian faculties: offering transparent and well-structured information, ensuring access to synchronous online teaching, and providing opportunities for social interaction with fellow students. It also reveals students' general preference for on-site teaching and their choice of asynchronous digital teaching over synchronous online teaching. There was a particular desire for the future use of teaching recordings to supplement on-site teaching. The most common concerns of students were the lack of possibility to perform practical trainings and the lack of social exchange with fellow students. 
At this point, we would like to reference to materials that we ourselves would have liked to have at hand some time earlier. When having to choose between various methods in medical education under pandemic conditions, Lim and colleagues' decision tree can be helpful [39]. For the implementation of digital medical education under COVID-19, we recommend the twelve practical tips by Jiang and colleagues [40]. A comparison between different digital communication tools and didactic approaches of several medical schools can be found in an article by Chatterjee and Chakraborty [41]. Recommendations for pandemic-compliant medical skills practice can be found in an article by Hall and colleagues [42]. Those involved in developing and administering student exams will find relevant assessment forms in Gupta and colleagues' overview, which also sheds light on the respective advantages and disadvantages in the context of the pandemic [43].

Our results on the organizational framework indicate that the Bavarian medical faculties, despite the challenging and constantly changing COVID-19 situation, have improved their information management in the course of the pandemic. The administrations of the medical faculties seem to be able to fall back on a certain resilience in their structures in this regard [44]. In addition, the student assessments of the organizational framework, which are in the upper middle range, indicate that the Bavarian medical faculties still have a need for development with regard to a more transparent and better-structured information policy. However, since we do not have comparative values concerning the situation of the organizational framework before COVID-19, it is difficult to assess how great the need for development of the administration actually is.

Even after the second COVID-19 semester, the data reveals that in terms of students' technical equipment and access to a stable internet connection, a nonnegligible proportion of students are unable to participate in synchronous online sessions, or only to a limited extent. These students are at risk of being left behind - universities should find ways to compensate for social disadvantages in the use of digital media, otherwise worse-off students will be at an even greater disadvantage in the future than this is already the case [16]. The provision of teaching recordings of synchronous online sessions, pandemicfriendly workspaces with a stable internet connection and the expansion of university rental services for technical equipment such as laptops could have a cushioning effect here.

Students especially missed the personal contact with fellow students, but also with teachers. In the second COVID-19 semester this intensified further. Other surveys already reported that physical distancing and the shift to digital teaching decreased communication between students as well as students and faculty in comparison to teaching before the pandemic $[10,16,33]$. It can be concluded that universities should find ways to minimize the social isolation of their students when relying more on e-learning concepts in the future. While students kept in touch with each other mainly via WhatsApp and comparable instant messaging services, E-mails were the most important communication channel between students and teachers. In phases in which e-learning must be used primarily, it may be worth offering communication opportunities via video conferencing systems, to allow for somewhat more personal interaction. In the winter semester, presumably after working out suitable hygiene concepts, teachers were again able to offer more on-site meetings than in the summer semester. On-site meetings among students, on the other hand, decreased in the winter semester, which can be explained by contact restrictions in Bavaria. Over the course of the pandemic, students increasingly turned to video conferencing for peer-to-peer communication, which can also be seen as a good preparation for future online consultations.

Students did not evaluate the summer semester (first semester under COVID-19 conditions) as more exhausting than the previous semester with traditional on-site teaching. Similar is the case for the comparison between the two semesters under COVID-19 conditions: The winter semester 2020/21 was not rated as more exhausting than the preceding summer semester. Publications with a mental health focus nevertheless suggest pressures from studying in times of COVID-19 that should not be underestimated [26, 27].

The most frequently preferred form of teaching was on-site teaching, which probably reflects the desire for personal contact. The fact that asynchronous digital teaching was preferred over synchronous online teaching could be explained by the desire for temporal flexibility, which is especially critical for student crisis workers. While the preference for on-site teaching increased in the winter semester, the preference for digital teaching formats decreased. This could be due to the permanent burden of the pandemic and "webinar fatigue" [45].

The most popular online activity to supplement future on-site sessions is teaching recordings, although these declined in popularity somewhat in the winter semester. Scripts, etc. (e.g. slides, summary, journal article) ranked second, and online self-tests ranked third. These frequently chosen online activities allow students flexibility in time and location, as well as the opportunity to study at their own pace. This explanation is in line with results of Dost and colleagues [5]. In addition, online self-tests can be used to check one's own level of knowledge and receive (automated) feedback. In their scoping review, Katz and Nandi point to the largely untapped potential of social media in medical education [46]. However, there was no checkbox to select this in the questionnaire used.

The biggest concern of students during the summer semester was the lack of possibility to perform practical trainings. Depending on the pandemic situation, practical training in small groups with a strict hygiene concept or creative digital substitutes can provide a remedy. During the winter semester, the biggest concern of students was the lack of social exchange with fellow students. At another German university (Universität Hamburg), the loss of direct interaction was also seen as a major cause for concern by students [47]. Working with breakout rooms within video conferences is one approach to providing students with a platform for social exchange. Another result of this study was that retrospectively reported concerns related to the beginning of the semester were always higher than prospective concerns related to the following semester. At this point, the retrospective assessment method of concerns could be criticized. However, when interpreting the differences between semesters in terms of content, the experience gained during the semester may have reassured students about the following semester.

The results of the present study should be considered in light of its limitations. Regarding the study design, individual students could not be identified due to data protection regulations, and no pseudonyms were used. Thus, we are not dealing with completely the same collective in the two survey waves, which is why a statistical test for unconnected samples was applied. In addition, the findings are based on cross-sectional data and therefore cannot predict

Page 6/14 
whether the negative effects found for students from the COVID-19 pandemic will have a long-term impact on students' learning and success. Here, for example, future exam grades will need to show whether the COVID-19 pandemic has a long-term negative impact on our students. Last but not least and due to site specifics, data for some sites is only available for certain semesters of study or only for the second semester under COVID-19 conditions.

An open research question relates to medical students' perceptions of examinations during the COVID-19 pandemic. Investigating students' preferences for teaching design in post-COVID-19 times, which should be anchored in the curriculum, is another interesting research topic. What should be the "new normal" in medical training after the pandemic? Which of the advantages observed by the students should find their way into medical teaching on a permanent basis and which prerequisites still have to be fulfilled for this? It is therefore very important to clarify which competencies medical teachers need in order to be prepared for the future. In addition, the needs of medical faculties, for example in terms of technological infrastructure, should be explored more closely in order to create better conditions for digital teaching and learning and to develop greater adaptability to future requirements.

It appears that the COVID-19 pandemic will be with us for some time to come. In order to determine the most appropriate digital teaching methods for medical education, it is critical to involve students in the shaping of the learning design [48] and to further evaluate student performance on a regular basis [14]. A high degree of digital preparedness in medical education will be required in the future, not only in the event of further health crises [49], but also in adapting to impacts of the climate crisis [50].

\section{Conclusions}

This study presents student perceptions of primarily digital medical education during the first two semesters impacted by the COVID-19 pandemic at Bavarian faculties. Areas for improvement emerged in terms of information dissemination and ensuring access to synchronous online teaching for all students. In the future, students would like to see primarily on-site teaching supplemented by teaching recordings. Faculties should take students' concerns seriously and ensure opportunities to perform practical trainings and for social exchange with fellow students. This would also increase the level of digital preparedness in medical schools. Future research should address what medical students expect from teaching after COVID-19 and explore the extent to which structural and teaching frameworks need to evolve.

\section{List Of Abbreviations}

COVID-19

Coronavirus SARS-CoV-2

BEME

Best Evidence Medical Education

CHE

Centrum für Hochschulentwicklung

DZHW

Deutsches Zentrum für Hochschul- und Wissenschaftsforschung

HIS

Institut für Hochschulentwicklung

KMB

Kompetenznetz Medizinlehre Bayern

UniA

Universität Augsburg

FAU

Friedrich-Alexander-Universität Erlangen-Nürnberg

LMU

Ludwig-Maximilians-Universität München

TUM

Technische Universität München

UR

Universität Regensburg

JMU

Julius-Maximilians-Universität Würzburg

$n$

sample size

$S D$

standard deviation

$p$

$\mathrm{p}$-value

$M$

mean value. 


\section{Declarations}

\section{Ethics approval and consent to participate}

The ethics committee of each study site approved the conduct of the study or waived further review. The ethics committee of the Technical University of Munich (No. 31/21 S) and the ethics committee of the Ludwig-Maximilians-Universität Munich (No. 20-1151, approving for the Ludwig-MaximiliansUniversity Munich and for the University of Augsburg), approved the study methods. The ethics committee of the University of Regensburg and the ethics committee of the Friedrich-Alexander-Universität Erlangen Nürnberg waived further review as the project had been approved by the ethics committee of the Ludwig-Maximilians-Universität München before. The ethics committee of the University of Würzburg waived further review and also referred to the vote of the ethics committee of the Ludwig-Maximilians-Universität of Munich, stating that in principle there are no objections to the implementation of such projects. All Methods were caried out in accordance with relevant guidelines and regulations. Informed consent was obtained from participants at the beginning of the questionnaire.

\section{Consent for publication}

Not applicable

\section{Availability of data and materials}

The datasets generated and analyzed during the current study are not publicly available to prevent comparability of evaluation data between individual study sites. The full aggregated dataset can be found in the supplement. Free text comments cannot be provided for data protection reasons. Should data from the dataset be required, Dr. Christopher Holzmann-Littig can be contacted at christopher.holzmann-littig@mri.tum.de.

\section{Competing interests}

The authors declare that they have no competing interests.

\section{Funding}

The study was not funded. A translation service was used to proofread the manuscript in English. This was financed with budget funds of the Institute for Medical Education at the University Hospital of LMU Munich.

\section{Authors' contributions}

$\mathrm{JH}$ and LU provided the items for the core questionnaire. All authors were responsible for data collection at their own site. NZ researched the relevant literature. $\mathrm{CH}-\mathrm{L}$ performed the data analysis and interpretation. $\mathrm{CH}-\mathrm{L}$ and/or NZ created the figures/diagrams. $\mathrm{CH}-\mathrm{L}$, JH and NZ wrote the first draft of the manuscript. All authors critically reviewed, revised and approved the manuscript.

\section{Acknowledgments}

The research team would like to sincerely thank the students who took the time to provide us with valuable feedback on digital teaching under these exceptional conditions. We would also like to thank our colleagues within the six medical faculties in Bavaria, who were always available to provide us with advice and support. Many thanks also go to Mr. Alexander Prievert, who supported us with his proofreading service.

\section{Author details}

${ }^{1}$ TUM Medical Education Center, Faculty of Medicine, Technical University of Munich, Munich, Germany

${ }^{2}$ Department of Nephrology, University Hospital rechts der Isar, Faculty of Medicine, Technical University of Munich, Munich, Germany

${ }^{3}$ Institute of Medical Teaching and Medical Education Research, University Hospital of Würzburg, Würzburg, Germany

${ }^{4}$ Simulated Patient Program, Faculty of Medicine, Julius-Maximilians-Universität of Würzburg, Würzburg, Germany

${ }^{5}$ Institute for Medical Education, University Hospital, Ludwig-Maximilians-Universität Munich, Munich, Germany

${ }^{6}$ Faculty of Medicine, Dean's Office and Department of Medical Education Augsburg DEMEDA, Augsburg University, Augsburg, Germany

${ }^{7}$ Faculty of Medicine, Office of the Dean for Student Affairs, Friedrich-Alexander-Universität Erlangen-Nürnberg, Erlangen, Germany

${ }^{8}$ Faculty of Medicine, Dean's Office, University of Regensburg, Regensburg, Germany

\section{References}

1. World Health Organization. Considerations for implementing and adjusting public health and social measures in the context of COVID-19: Interim guidance. 2021. https://www.who.int/publications/i/item/considerations-in-adjusting-public-health-and-social-measures-in-the-context-of-covid-19- 
interim-guidance.

2. Berghoff S, Horstmann N, Hüsch M, Müller K. Studium und Lehre in Zeiten der Corona-Pandemie: Die Sicht von Studierenden und Lehrenden. Gütersloh; 2021.

3. Alkhowailed MS, Rasheed Z, Shariq A, Elzainy A, El Sadik A, Alkhamiss A, et al. Digitalization plan in medical education during COVID-19 lockdown. Inform Med Unlocked. 2020;20:100432. doi:10.1016/j.imu.2020.100432.

4. Alsoufi A, Alsuyihili A, Msherghi A, Elhadi A, Atiyah H, Ashini A, et al. Impact of the COVID-19 pandemic on medical education: Medical students' knowledge, attitudes, and practices regarding electronic learning. PLoS One. 2020;15:e0242905. doi:10.1371/journal.pone.0242905.

5. Dost S, Hossain A, Shehab M, Abdelwahed A, Al-Nusair L. Perceptions of medical students towards online teaching during the COVID-19 pandemic: a national cross-sectional survey of 2721 UK medical students. BMJ Open. 2020;10:e042378. doi:10.1136/bmjopen-2020-042378.

6. Mikuteit M, Steffens S, Grigull L, Kühnle L, Behrends M, Schmidt R, Mücke U. Rapid development of a digital module during the Covid 19 pandemic in undergraduate medical education of pediatrics by teachers and students. GMS J Med Educ. 2020;37:Doc66. doi:10.3205/zma001359.

7. Lörz M, Marczuk A, Zimmer L, Multrus F, Buchholz S. Studieren unter Corona - Bedingungen: Studierende bewerten das erste Digitalsemester: Deutsches Zentrum für Hochschul- und Wissenschaftsforschung (DZHW); 2020.

8. Ibrahim G, Luzinge H, Kapanda G. Teaching and Learning Experiences in Medical Education During the COVID-19 Pandemic: The Case of Kilimanjaro Christian Medical University College (KCMUCo), Tanzania. Journal of Learning for Development. 2020:433-46.

9. Cheng X, Chan LK, Pan S-Q, Cai H, Li Y-Q, Yang X. Gross Anatomy Education in China during the Covid-19 Pandemic: A National Survey. Anat Sci Educ. 2021;14:8-18. doi:10.1002/ase.2036.

10. Al-Balas M, Al-Balas HI, Jaber HM, Obeidat K, Al-Balas H, Aborajooh EA, et al. Distance learning in clinical medical education amid CovID-19 pandemic in Jordan: current situation, challenges, and perspectives. BMC Med Educ. 2020;20:341. doi:10.1186/s12909-020-02257-4.

11. Hodges C, Moore S, Lockee B, Trust T, Bond A. The Difference Between Emergency Remote Teaching and Online Learning. 2020. https://er.educause.edu/articles/2020/3/the-difference-between-emergency-remote-teaching-and-online-learning.

12. Wilcha R-J. Effectiveness of Virtual Medical Teaching During the COVID-19 Crisis: Systematic Review. JMIR Med Educ. 2020;6:e20963. doi:10.2196/20963.

13. Dedeilia A, Sotiropoulos MG, Hanrahan JG, Janga D, Dedeilias P, Sideris M. Medical and Surgical Education Challenges and Innovations in the COVID19 Era: A Systematic Review. In Vivo. 2020;34:1603-11. doi:10.21873/invivo.11950.

14. Kelly K, Hwei LRY, Octavius GS. Coronavirus outbreaks including COVID-19 and impacts on medical education: a systematic review. J Community Empowerment for Health. 2020;3:130. doi:10.22146/jcoemph.57082.

15. Jones S, Chacko S. Quantitative Analysis of the Evolving Student Experience During the Transition to On-Line Learning: Second-Language STEM Students. JoTLT. 2021;10:373-385. doi:10.14434/jotlt.v9i2.31401.

16. Katz VS, Jordan AB, Ognyanova K. Digital inequality, faculty communication, and remote learning experiences during the COVID-19 pandemic: A survey of U.S. undergraduates. PLoS One. 2021;16:e0246641. doi:10.1371/journal.pone.0246641.

17. Motte-Signoret E, Labbé A, Benoist G, Linglart A, Gajdos V, Lapillonne A. Perception of medical education by learners and teachers during the COVID-19 pandemic: a cross-sectional survey of online teaching. Med Educ Online. 2021;26:1919042. doi:10.1080/10872981.2021.1919042.

18. Olum R, Atulinda L, Kigozi E, Nassozi DR, Mulekwa A, Bongomin F, Kiguli S. Medical Education and E-Learning During COVID-19 Pandemic: Awareness, Attitudes, Preferences, and Barriers Among Undergraduate Medicine and Nursing Students at Makerere University, Uganda. J Med Educ Curric Dev. 2020;7:2382120520973212. doi:10.1177/2382120520973212.

19. Ponti R de, Marazzato J, Maresca AM, Rovera F, Carcano G, Ferrario MM. Pre-graduation medical training including virtual reality during COVID-19 pandemic: a report on students' perception. BMC Med Educ. 2020;20:332. doi:10.1186/s12909-020-02245-8.

20. Gintrowicz R, Pawloy K, Richter J, Degel A. Can we adequately teach ethics and ethical decision making via distant learning? A pandemic pilot. GMS J Med Educ. 2020;37:Doc80. doi:10.3205/zma001373.

21. Fischbeck S, Hardt J, Malkewitz C, Petrowski K. Evaluation of a digitized physician-patient-communication course evaluated by preclinical medical students: a replacement for classroom education? GMS J Med Educ. 2020;37:Doc85. doi:10.3205/zma001378.

22. Knie K, Schwarz L, Frehle C, Schulte H, Taetz-Harrer A, Kiessling C. To zoom or not to zoom - the training of communicative competencies in times of Covid 19 at Witten/Herdecke University illustrated by the example of "sharing information". GMS J Med Educ. 2020;37:Doc83. doi:10.3205/zma001376.

23. Lenes A, Klasen M, Adelt A, Göretz U, Proch-Trodler C, Schenkat H, Sopka S. Crisis as a chance. A digital training of social competencies with simulated persons at the Medical Faculty of RWTH Aachen, due to the lack of attendance teaching in the SARS-Cov-2 pandemic. GMS J Med Educ. 2020;37:Doc82. doi:10.3205/zma001375.

24. Swart E, Feißel A, Hasoon A, Hörold M, Hupach H, Matterne U, et al. Practical training in medical sociology "Analysis of social environments of living quarters". A field experiment during the COVID-19 pandemic. GMS J Med Educ. 2021;38:Doc27. doi:10.3205/zma001423.

25. Loda T, Löffler T, Erschens R, Zipfel S, Herrmann-Werner A. Medical education in times of COVID-19: German students' expectations - A cross-sectional study. PLoS One. 2020;15:e0241660. doi:10.1371/journal.pone.0241660.

26. Mittal R, Su L, Jain R. COVID-19 mental health consequences on medical students worldwide. J Community Hosp Intern Med Perspect. 2021;11:296-8. doi:10.1080/20009666.2021.1918475. 
27. Guo AA, Crum MA, Fowler LA. Assessing the Psychological Impacts of COVID-19 in Undergraduate Medical Students. Int J Environ Res Public Health 2021. doi:10.3390/ijerph18062952.

28. Ashcroft J, Byrne MHV, Brennan PA, Davies RJ. Preparing medical students for a pandemic: a systematic review of student disaster training programmes. Postgrad Med J. 2021;97:368-79. doi:10.1136/postgradmedj-2020-137906.

29. Martin A, Blom IM, Whyatt G, Shaunak R, Viva MIF, Banerjee L. A Rapid Systematic Review Exploring the Involvement of Medical Students in Pandemics and Other Global Health Emergencies. Disaster Med Public Health Prep. 2020:1-13. doi:10.1017/dmp.2020.315.

30. Daniel M, Gordon M, Patricio M, Hider A, Pawlik C, Bhagdev R, et al. An update on developments in medical education in response to the CoVID-19 pandemic: A BEME scoping review: BEME Guide No. 64. Med Teach. 2021;43:253-71. doi:10.1080/0142159X.2020.1864310.

31. Harries AJ, Lee C, Jones L, Rodriguez RM, Davis JA, Boysen-Osborn M, et al. Effects of the COVID-19 pandemic on medical students: a multicenter quantitative study. BMC Med Educ. 2021;21:14. doi:10.1186/s12909-020-02462-1.

32. Park H, Lee Y-M, Ho M-J, Han H-C. How the coronavirus disease 2019 pandemic changed medical education and deans' perspectives in Korean medical schools. Korean J Med Educ. 2021;33:65-74. doi:10.3946/kjme.2021.187.

33. Bosse E, Lübcke M, Book A, Würmseer G. Corona@Hochschule: Befragung von Hochschulleitungen zur (digitalen) Lehre. 2020. https://hishe.de/index.php? elD=tx_securedownloads\&p=131\&u=0\&g=0\&t=1634750196\&hash=8bd4637f51cf934f68071e00be298ebb8c701288\&file=/fileadmin/user_upload/HISHE_Medium_7_2020_Corona\%40Hochschule.pdf.

34. Bosse E. Fachbereiche und Fakultäten in der Corona-Pandemie. Erfahrungen und Erwartungen an die Zukunft. 2021. https://hochschulforumdigitalisierung.de/sites/default/files/dateien/HFD_AP_57_Fachbereiche_digitale_Lehre_Corona.pdf.

35. Eysenbach G. Improving the quality of Web surveys: the Checklist for Reporting Results of Internet E-Surveys (CHERRIES). J Med Internet Res. 2004;6:e34. doi:10.2196/jmir.6.3.e34.

36. JASP Team. JASP (Version 0.14.1) [Computer software]; 2021.

37. GraphPad QuickCalcs. https://www.graphpad.com/quickcalcs/contingency1/. Accessed 7 Nov 2021.

38. Hijmans RJ, van Etten J. raster: Geographic Data Analysis and Modeling; 2021.

39. Lim ECH, Oh VMS, Koh D-R, Seet RCS. The challenges of "continuing medical education" in a pandemic era. Ann Acad Med Singap. 2009;38:724-6.

40. Jiang Z, Wu H, Cheng H, Wang W, Xie A, Fitzgerald SR. Twelve tips for teaching medical students online under COVID-19. Med Educ Online. 2021;26:1854066. doi:10.1080/10872981.2020.1854066.

41. Chatterjee I, Chakraborty P. Use of Information Communication Technology by Medical Educators Amid COVID-19 Pandemic and Beyond. Journal of Educational Technology Systems. 2021;49:310-24. doi:10.1177/0047239520966996.

42. Hall AK, Nousiainen MT, Campisi P, Dagnone JD, Frank JR, Kroeker KI, et al. Training disrupted: Practical tips for supporting competency-based medical education during the COVID-19 pandemic. Med Teach. 2020;42:756-61. doi:10.1080/0142159X.2020.1766669.

43. Gupta MM, Jankie S, Pancholi SS, Talukdar D, Sahu PK, Sa B. Asynchronous Environment Assessment: A Pertinent Option for Medical and Allied Health Profession Education During the COVID-19 Pandemic. Education Sciences. 2020;10:352. doi:10.3390/educsci10120352.

44. Embert U, Lenz T, Reimer M. Kongress für Hochschulinnovation: Kernelemente eines zukunftsfähigen Hochschulsystems. 2021. https://www.ihf.bayern.de/fileadmin/user_upload/Publikationen/IHF_Kompakt/lHF-kompakt-Oktober-2021.pdf.

45. Sharma MK, Sunil S, Anand N, Amudhan S, Ganjekar S. Webinar fatigue: fallout of COVID-19. J Egypt Public Health Assoc. 2021;96:9. doi:10.1186/s42506-021-00069-y.

46. Katz M, Nandi N. Social Media and Medical Education in the Context of the COVID-19 Pandemic: Scoping Review. JMIR Med Educ. $2021 ; 7:$ 25892. doi:10.2196/25892.

47. Bohndick C, Brase A, Kaufmann M, Lübcke E, Reinmann G, Zabolotna N. Emergency Remote Teaching im Sommersemester 2020: Bericht zur Begleitforschung - Hoffnungen und Befürchtungen der Studierenden. 2021. https://www.hul.uni-hamburg.de/dateien/begleitforschung-berichtlehrendenbefragung-barrierefrei.pdf.

48. Reyna J. Twelve Tips for COVID-19 friendly learning design in medical education. MedEdPublish 2020. doi:10.15694/mep.2020.000103.1.

49. Althwanay A, Ahsan F, Oliveri F, Goud HK, Mehkari Z, Mohammed L, et al. Medical Education, Pre- and Post-Pandemic Era: A Review Article. Cureus. 2020;12:e10775. doi:10.7759/cureus.10775.

50. Nikendei C, Cranz A, Bugaj TJ. Medical education and the COVID-19 pandemic - a dress rehearsal for the "climate pandemic"? GMS J Med Educ. 2021;38:Doc29. doi:10.3205/zma001425.

\section{Figures}




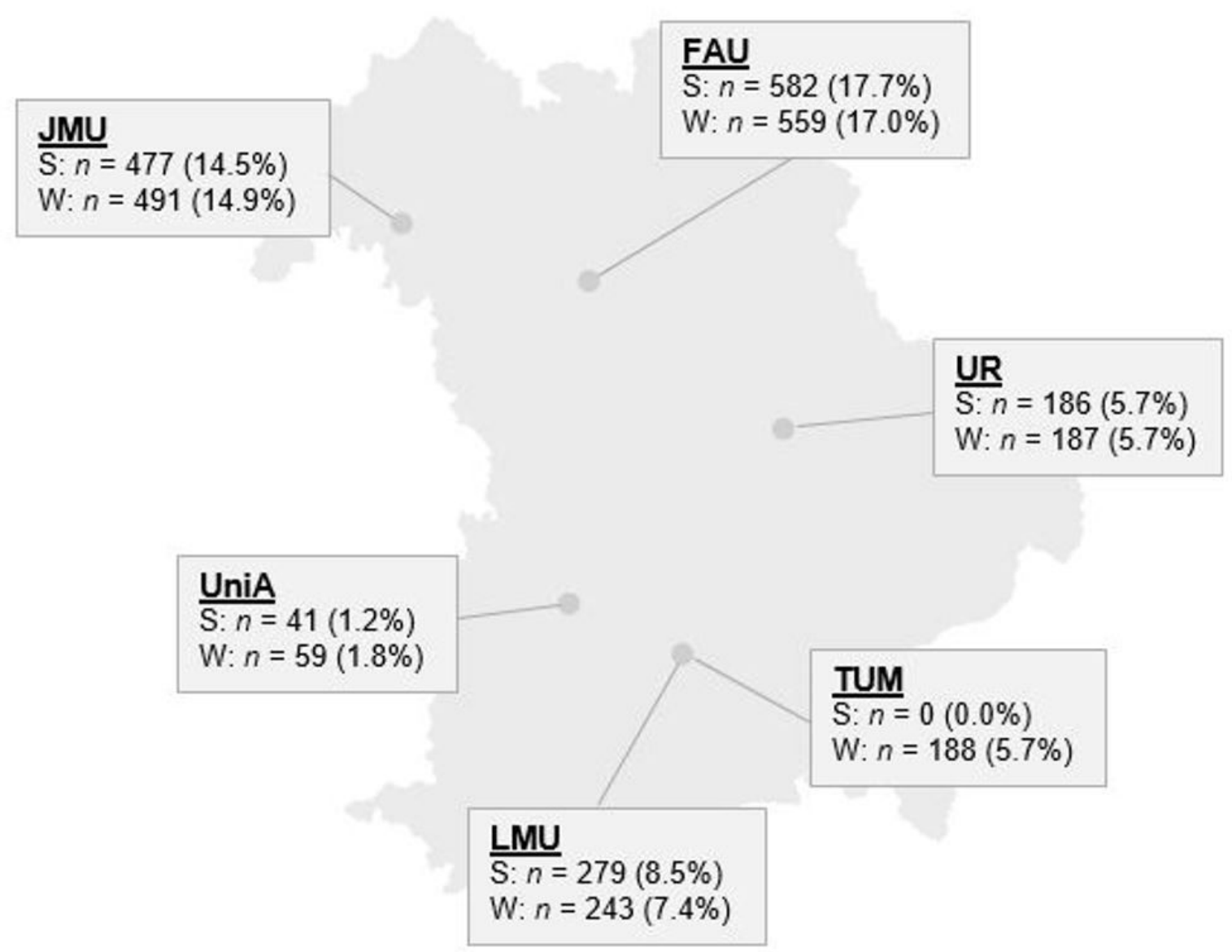

Figure 1

Number of data sets per site. Total participants: 3292. $n=$ number of participants per site, $\%=$ percent of total participants across both semesters; $\mathrm{S}=$ summer semester 2020, W = winter semester 2020/21, JMU = Julius-Maximilians-Universität Würzburg, FAU = Friedrich-Alexander-Universität ErlangenNürnberg, UR = Universität Regensburg, UniA = Universität Augsburg, TUM = Technische Universität München, LMU = Ludwig-Maximilians-Universität München. Percentages do not add up to $100 \%$ due to rounding. 
Figure 2a:

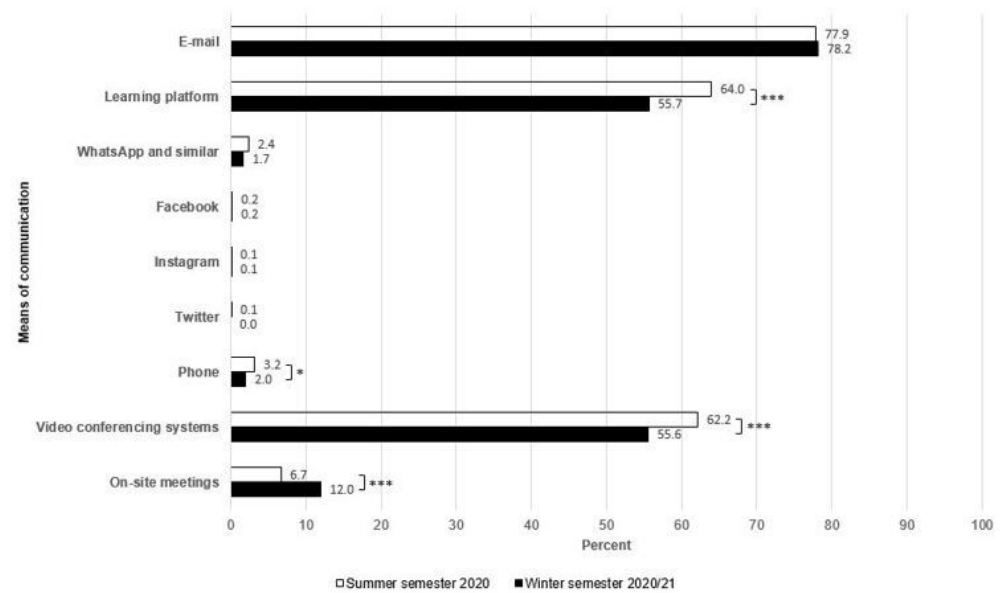

Figure 2b:

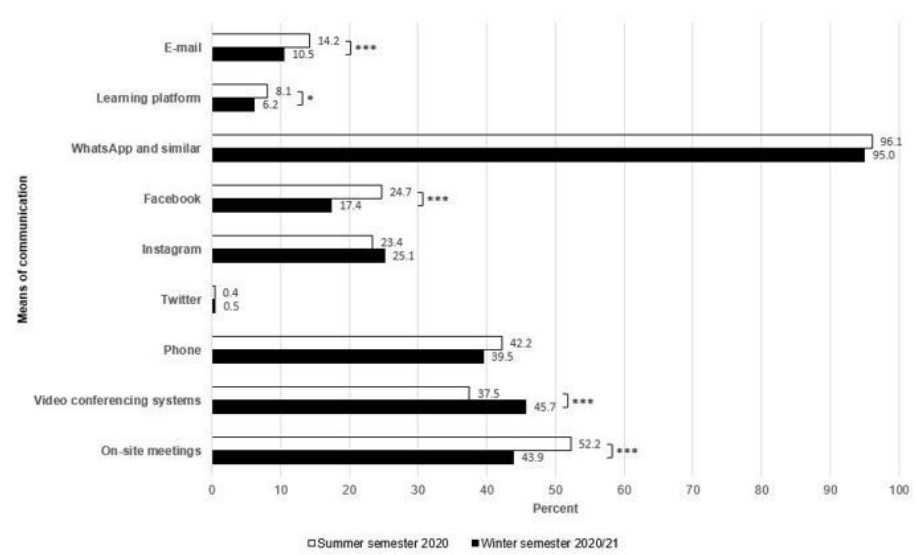

\section{Figure 2}

2a: Means of communication used between students and teachers

Notes: summer semester 2020: $n=1524$, winter semester 2020/21: $n=1727$; multiple selection possible; * $p \leq 0.05$; *** $p \leq 0.001$.

2b: Means of communication used between fellow students

Notes: summer semester 2020: $n=1524$, winter semester 2020/21: $n=1727$; multiple selection possible; * $p \leq 0.05 ; * \star * ~ p \leq 0.001$. 


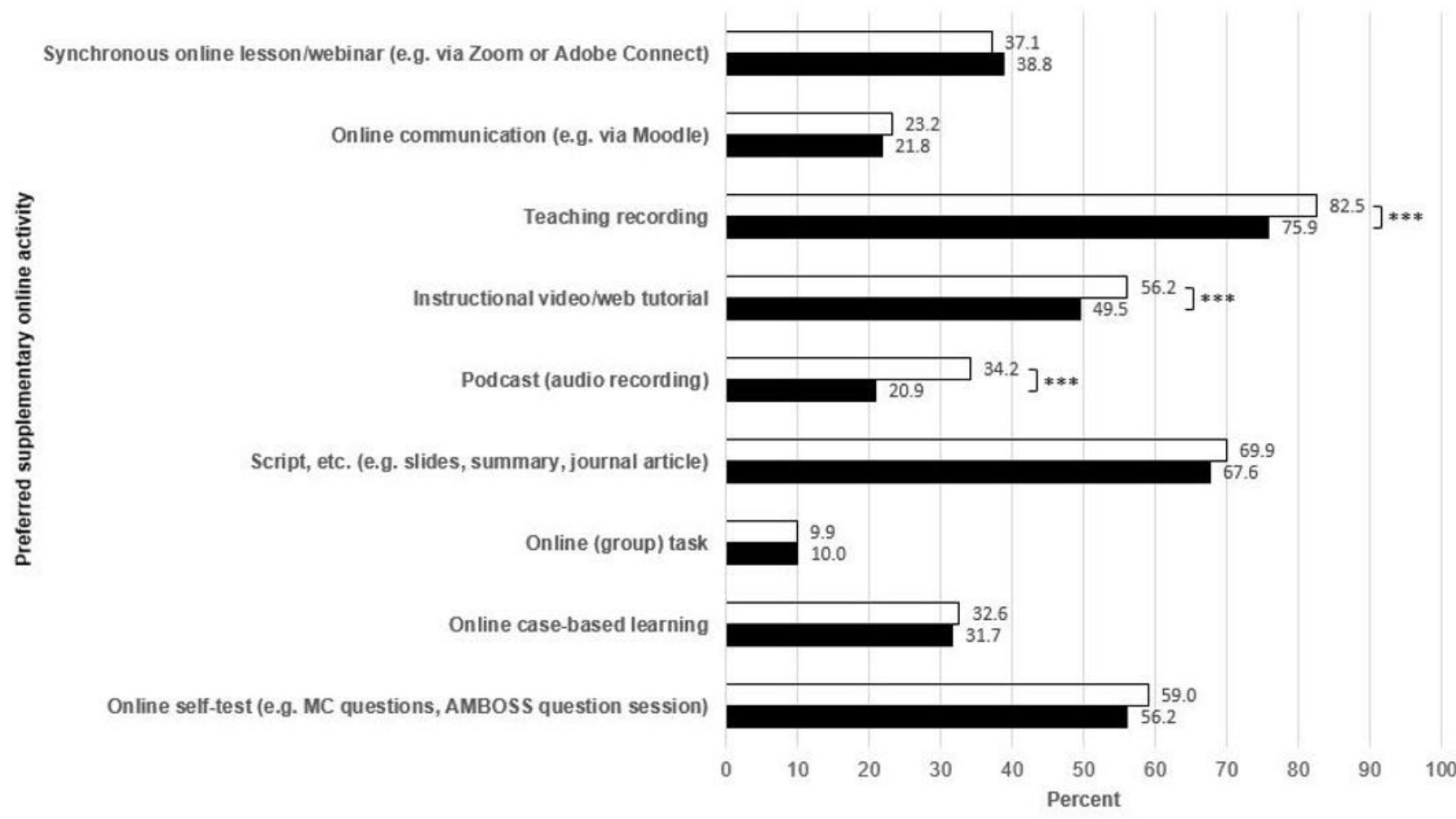

口Summer semester 2020 aWinter semester 2020/21

Figure 3

Evaluation of online activities to supplement traditional on-site teaching for future semesters

Notes: multiple selection possible; ${ }^{\star \star \star} p \leq 0.001$ 
Figure 4a:

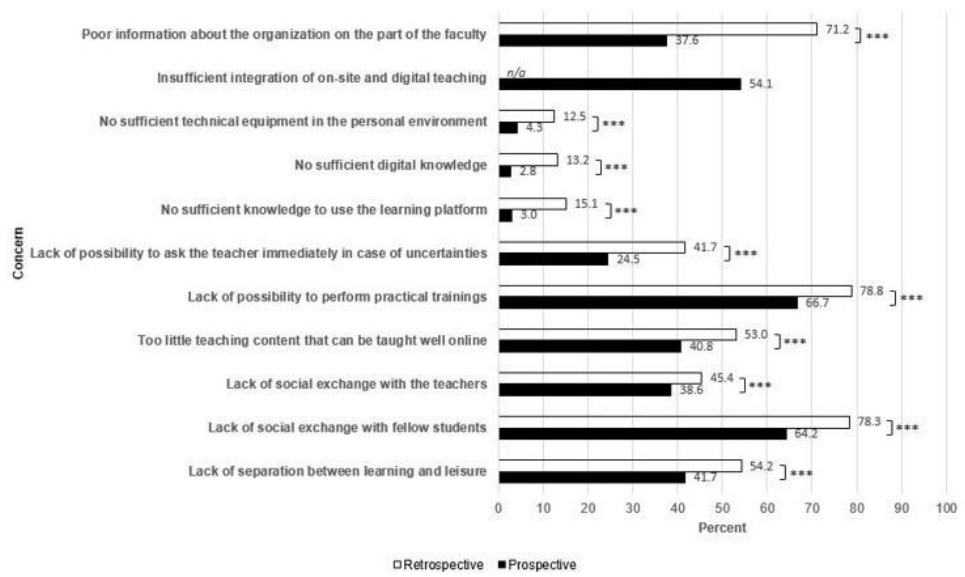

Figure 4b:

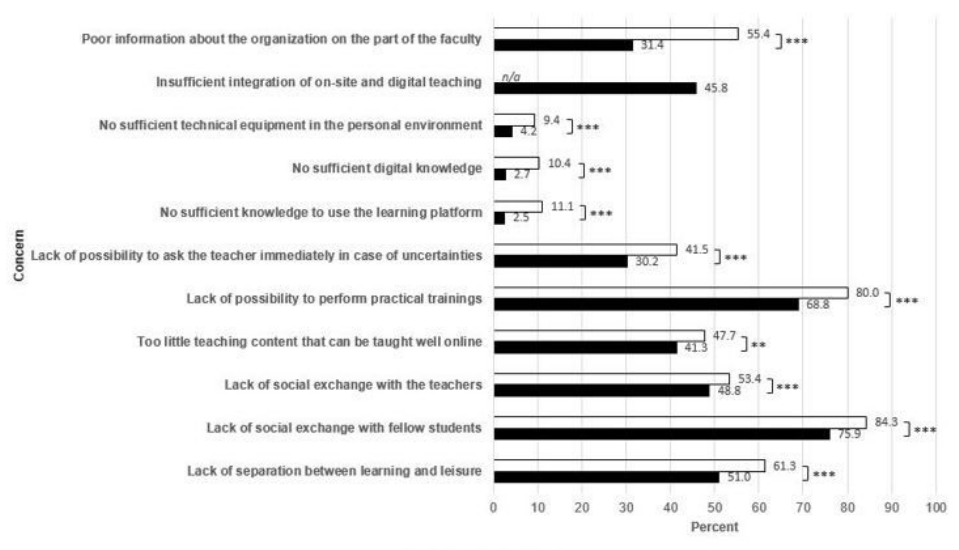

DRetrospective - Prospective

\section{Figure 4}

4a: Student concerns as surveyed at the end of the summer semester 2020

Notes: $n=1524$; retrospective = concerning the beginning of the summer semester 2020; prospective = concerning the upcoming winter semester 2020/21; multiple selection possible; ${ }^{* \star *} p \leq 0.001$.

4b: Student concerns as surveyed at the end of the winter semester 2020/21

Notes: $n=1727$; retrospective = concerning the beginning of the winter semester 2020/21; prospective = concerning the upcoming summer semester 2021; multiple selection possible; $* * 0.01 ; * \star * p \leq 0.001$.

\section{Supplementary Files}

This is a list of supplementary files associated with this preprint. Click to download.

- Supplement1questionnaireinGermanandEnglish.docx

- Supplement2CHERRIESchecklist.docx

- Supplement3quantitativeresults.docx 